\title{
Prevalence, risk factors and antimicrobial suscep- tibility profile of Salmonella isolated from dogs of Ambo, Bako and Gojo towns of West Shoa, Ethiopia
}

\author{
Endrias Zewdu Gebremedhin ${ }^{* 1}$, Sisay Miheretu ${ }^{2}$, Lencho Megersa ${ }^{3}$,Edilu Jorga \\ Sarba $^{1}$, Getachew Kebebew ${ }^{1}$ and Solomon Shiferaw ${ }^{3}$ \\ ${ }^{1}$ Department of Veterinary Sciences, College of College of Agriculture and Veterinary Science, \\ Ambo University, P.O.Box 19, Ambo, Ethiopia. \\ ${ }^{2}$ Department of Animal Production and Technology, College of Agricultural Sciences, Welkite \\ University, P.O.Box 07, Welkite,Guragie Zone, SNNPR, Ethiopia. \\ ${ }^{3}$ Department of Veterinary Laboratory Technology, College of Agriculture and Veterinary Science, \\ Ambo University, P.O.Box 19, Ambo, Ethiopia \\ *Corresponding author: Endrias Zewdu Gebremedhin endrias.zewdu@gmail.com,
}

\begin{abstract}
Salmonella is the most known zoonotic bacterial agent, which produces salmonellosis in animals as wells as in humans. The objectives of this study were to estimate the prevalence, to determine antimicrobial susceptibility and to assess risk factors associated with Salmonella shedding in dogs in selected towns of West Shoa Zone, Oromia, Ethiopia. Using a cross-sectional design, a total of 438 rectal swab samples were collected from randomly selected dogs for isolation and identification of Salmonella using standard procedures. A questionnaire survey was also administered. The results showed that 48 (11.0\%, 95\%, [CI]: $8.2 \%-14.3 \%$ ) dogs were positive for Salmonella. The occurrenceof Salmonella was 10.9\% (26/238), 11.6\% (15/129) and 9.9\% (7/71) in Ambo, Bako and Gojo towns respectively. Salmonella shedding was significantly higher in older dogs $(15.0 \%)$ than younger ones $(6.1 \%)(P<0.05)$. The occurrence of Salmonella was not significantly associated with study towns, sex, breed of dogs,educational level of owners, presence of other domestic animals and housing system $(P>0.05)$. Multivariable logistic regression analysis showed that the odds of isolation of Salmonella was significantly higher in old than young dogs $(\mathrm{OR}): 2.6,95 \% \mathrm{CI}: 1.3-5.6, P=0.007)$ and in dogs eating mixed type of feeds (raw animal products, household leftover) than cooked feed (OR =9.0, 95\% CI: $1.2-$ 68.1, $P=0.033)$. There was also a significant difference between kebeles of the study areas in that Salmonella isolation was nearly nine times higher in Bako Kebele $02(P=0.005)$ as compared to Ambo kebele 03. Salmonella isolates have developed the highest level of resistance for ampicillin (100\%), tetracycline
\end{abstract}


(93.3\%) and streptomycin (80.0\%), however, all isolates were susceptible to Norfloxacin. The occurrence of Salmonella, most of which resistant to commonly used antimicrobials, in rectal swab samples show the potential threat dogs may pose to public health in the study area.

Keywords: Antimicrobial Resistance; Dog; Ethiopia; Prevalence; Risk factor; Salmonella.

\section{Introduction}

Salmonella is the causative agent of both human and animal salmonellosis. The bacterium causes infections ranging from subclinical carrier status to acute fatal septicemia (Quinn et al., 2011). It is a potential cause of acute and chronic diarrhea and death in numerous animal species and in human beings (McGavin et al., 2001). About 22 million diseases and 220,000 deaths were reported globally during 2000 as the result of typhoid fever (Crump et al., 2004) and 93.8 million illness of gastroenteritis and 155,000 deaths due to non-typhoidal Salmonella (Kirk et al., 2015). The main source of infection for Salmonella to human is feces of almost all animals including pets that have intimate relationships with humans (Ojo and Adetosoye, 2009).

The prevalence of subclinical carriage of Salmonella in apparently healthy dogs varies greatly among individual countries and has been reported to range from 0 to $44 \%$ (Carter and Quinn, 2000). Most cases of Salmonella infections in dogs are latent and subclinical (Kozak et al., 2003). More than one-third of healthy dogs have Salmonellain their digestive tract and shed the organisms (Finley et al., 2007). High numbers of the microorganism can reside in the intestines and mesenteric lymph nodes without clinical signs making an estimate of the prevalence of Salmonella in dogs in the community difficult to establish. Nevertheless, clinical cases of salmonellosis when seen is often associated with hospitalization, another infection or debilitating conditions in adults, or exposure manifested by watery or mucoid diarrhea with blood in severe cases, vomiting, fever, anorexia, lethargy, abdominal pain and progressive dehydration (Carter and Quinn, 2000).

In developing countries, control of antimicrobial-resistant infections in both humans and animals are of a great challenge because of inadequate adherence to prudent use of antimicrobials, unhygienic living conditions, close con- 
tact and sharing of houses between animals and humans (Feasey et al., 2012). Different scholars reported antimicrobial resistant Salmonella isolates from categories of food (Weldo et al., 2015; Ejo et al., 2016), animal (Abdi et al., 2017; Kiflu et al., 2017) and human (Eguale et al., 2015; Marami et al., 2018) specimens in Ethiopia. There is an increasing concern with this pathogen due to the emergence and spread of antimicrobial-resistant and potentially more pathogenic strains (WHO, 2012).

Salmonellosis influences the economy of both developing and developed countries through incurring a cost in relation to surveillance, prevention and treatment (Crump et al., 2004) that requires epidemiological and microbiological investigation. Information about the isolation, risk factors for sheddingand antibiogram of Salmonella species in dogs is scarce in Ethiopia in general and totally absent in the current study areas (Ambo, Bako and Gojo towns). In this aspect, the investigation of Salmonella in dogs was thought to be important to see the contribution of dogs as a potential source of zoonotic Salmonella to humans. Therefore, the objectives of the present study were to estimate the prevalence of Salmonella in dogs, to assess the major risk factors and to determine antimicrobial susceptibility of the isolates.

\section{Materials and methods}

\section{Study area}

The study was conducted in three towns of West Shoa Zone of Oromia Region from December 2016 to April 2017 (Figure 1). These towns are namely Ambo, Gojo and Bako. Ambo is the administrative center of Ambo district and West ShoaZone located $114 \mathrm{Km}$ West of Addis Ababa, the capital city of Ethiopia. The town had a total human population of 74, 843 out of which 39,192 are male and 35,651 are female. Ambo Zuria (Zuria; around) district has 110,952 cattle, 87,817 sheep, 48,937 goats, 3,419 equines and 40,971 chickenpopulations. Bako town, the administrative center of Bakotibe district is located $260 \mathrm{Km}$ West of Addis Ababa.Based on figures from the Central Statistical Agency in 2005, Bako has an estimated total population of 18,641 of whom 9,370 are men and 9,271 women. Bakotibe district has 137,343 cattle, 12,502 sheep, 24,212 goats, 3,685 horses, 8,415 donkeys, 1,023 mule and 96,742 poultry (Bekele and Kebede, 2016). Likewise, Gojo town is the administrative center of Jeldu district of West Shoa Zone located $120 \mathrm{Km}$ West of Addis Ababa.The human population of Jeldu district is 202,655 of which 102,796 are females and the remaining 99,859 males (CSA, 2008).Jeldudistrict has a total population of 
78,300 cattle, 50,450 sheep, 25,560 goats, and 45,210 equine species.There was no accessible recorded statistical information on dog population in the study areas. The three towns have bimodal rainfall characterized by a small rainy season from February to May and a big rainy season from July to September. The dry season extends from October to January (CSA, 2007; CSA, 2015).

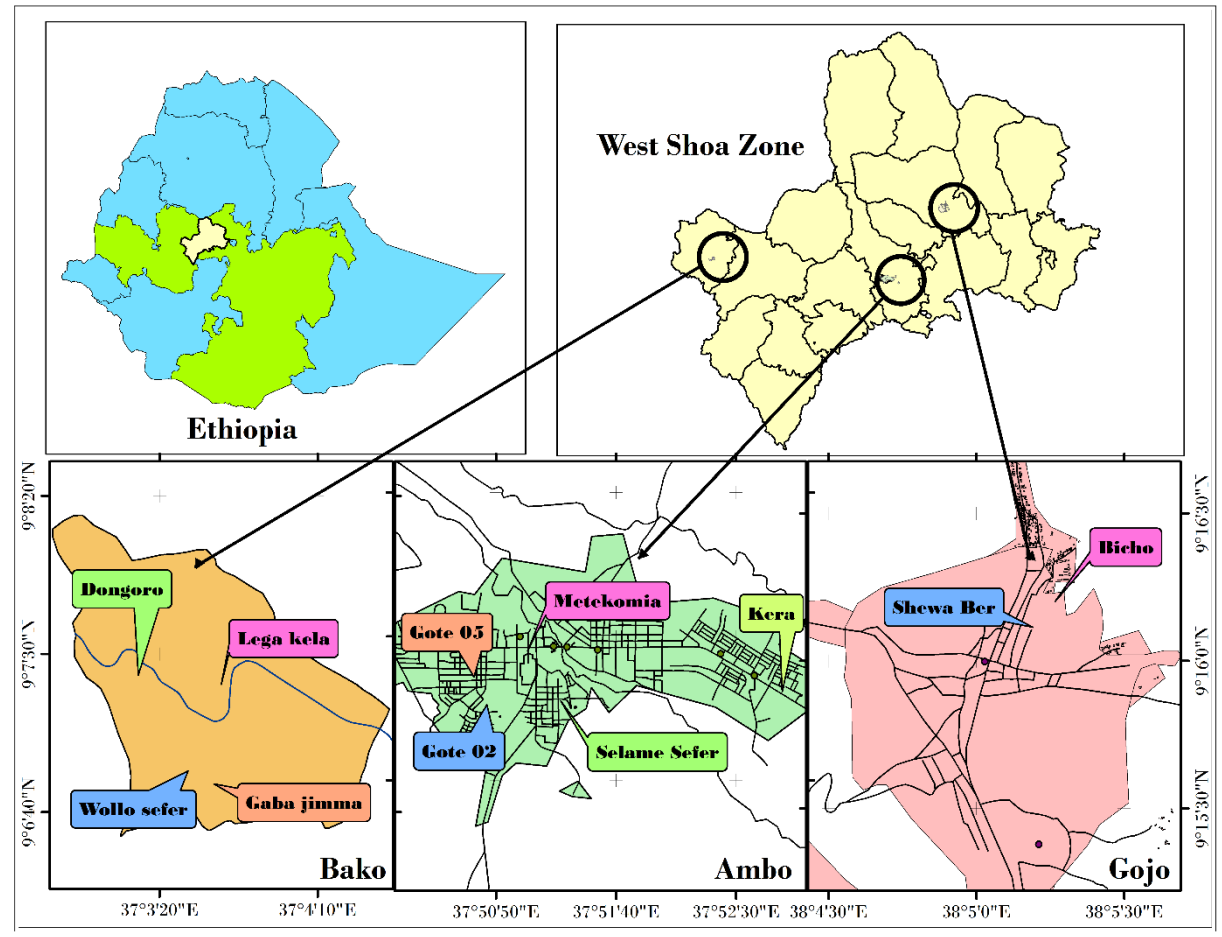

Figure 1. Map of the study towns indicating sampled Kebeles

\section{Study population}

The study population was all dogs found in the Ambo, Bako and Gojo towns. Apparently healthy dogs of differentage groups, breed and bothsexesfound in the selected Kebeles (the smallest formal administrative unit of a town) of the three towns were considered as the target population. 


\section{Study design}

A cross-sectional study was conducted to assess the prevalence of Salmonella from rectal swab samples of dogs. The total sample size was divided into the three towns proportionally depending on the number of Kebeles. In each Kebeles, Gotes were approached (a Gote is a subset of Kebele comprising up to 50 households). Ambo, Bako and Gojo towns have three, two and one Kebeles respectively. From each Kebele, two Gotes were randomly selected.Twelve Gotes were selected with an almost equal number of samples in order to decrease bias.

\section{Sample size determination}

The sample size was determined using the formula described by Thrusfield (2007) with the assumption of 50\% expected prevalence, 95\% confidence interval and $5 \%$ absolute precision.

Where $\mathrm{n}=$ required sample size, $\mathrm{p}=$ expected prevalence $\mathrm{d}=$ desired absolute precision. Therefore, the calculated sample size was 384 . About $15 \%$ of the calculated sample size was additionally taken to reduce the risk of sample loss during analysis. Thus, the total sample size in this study was 438 .

\section{Sample collection}

Rectal swab sample was collected from each dog after proper restraining. Thirty samples were collected and processed per week and 438 samples were collected from different sources. The samples were collected in sterile buffered peptone water (HiMedia, India) using sterile swabs and transported to Ambo University Veterinary Laboratory in icebox containing ice packs.

\section{Questionnaire survey}

A pre-tested questionnaire was administered for dog owners in order to collect information about management risk factors such as feeding (cooked animal products and mixed [raw meat, cooked animal products and household left over]), housing (indoor, outdoor and mixed type), educational status of owners (Illiterate, Elementary School, Secondary School, and Tertiary/University), treatment status of dogs with antibiotics (treated and not treated), presence of other animals (present and absent) within the same household, breed and 
age of dogs. Age was categorized as young (dogs of less than and equal to two years) and adult (more than two years) (Wikipedia, 2019).

\section{Inclusion and exclusion criteria}

Accessible dogs whose owners are willing for sampling were included in the study while critically sick dogs and those under treatment were excluded.

\section{Isolation and identification of Salmonella}

Isolation and identificationof Salmonella from rectal swab samples were performed according to the procedure recommended by the international standard organization (ISO) for isolation of Salmonella (ISO 6579, 2007). Briefly, rectal swab samples were transferred into a tube with $9 \mathrm{ml}$ of buffered peptone water (HiMedia, India), shaken for approximately 2 minutes and incubated at $37 \pm 1^{\circ} \mathrm{C}$ for $18 \pm 2 \mathrm{~h}$. A portion of the culture $(0.1 \mathrm{ml})$ was transferred to a tube containing $10 \mathrm{ml}$ selective enrichment liquid media (Rappaport-Vassiliadis, HiMedia, India) and incubated at $42^{\circ} \mathrm{C}$ for $24 \pm 3 \mathrm{~h}$. Similarly, $1 \mathrm{ml}$ of the culture was transferred to a tube containing $10 \mathrm{ml}$ of Tetrathionate broth (Conda S.A., Spain) and incubated at $37^{\circ} \mathrm{C}$ for $24 \pm 3 \mathrm{~h}$. A loopful of inoculum from each of enrichment cultures was then inoculated on the surface of two different plates, viz. xylose lysine deoxycholate (XLD) agar (Sisco research lab, India) and brilliant green agar (BGA) (HiMedia, India) and then incubated at $37^{\circ} \mathrm{C}$ for $24 \pm 3$ h. For confirmation, presumptive Salmonella colonies from both XLD agar and BGA were selected and streaked onto the surface of pre-dried nutrient agar (Oxoid, England) plates and incubated at $37^{\circ} \mathrm{C}$ for $24 \pm 3 \mathrm{~h}$. Colonies from nutrient agar were inoculated into the following biochemical tubes for identification: triple sugar iron (TSI) agar (HiMedia, India), lysine iron agar (Conda S.A., Spain), Simmon's citrate agar (HiMedia, India), urea broth (HiMedia, India), Sulphide Indole Motility (SIM) medium (Sisco research lab, India) and incubated for 24 or $48 \mathrm{~h}$ at $37^{\circ} \mathrm{C}$.

Colonies producing an alkaline (red) slant with acid (yellow) butt with hydrogen sulphide production (blackening) on TSI, positive for lysine (purple color with gas production), positive for citrate utilization (blue color), negative for urea hydrolysis (no color change) and negative for tryptophan utilization (Indole test) (yellow-brown ring) were considered asSalmonella (ISO 6579, 2002). 


\section{Antimicrobial susceptibility testing}

The pure Salmonella isolates confirmed by the biochemical testing procedures were tested for antimicrobial susceptibility. Antimicrobial susceptibility testing was done using the agar disk diffusion method as described by the Clinical Laboratory Standard Institute (CLSI, 2014).Fourto five well-isolated colonies from nutrient agar plates were transferred intotubes containing $5 \mathrm{ml}$ of nutrient broth (Conda S.A., Spain). The broth culturewas incubated at $37^{\circ} \mathrm{C}$ for 4-6 h until it achieved the 0.5 McFarland turbiditystandards. A sterile cotton swab was dipped into the suspension, rotated severaltimes, pressing firmly on the inside wall of the tube above the fluid level toremove excess inoculum and swabbed uniformly over the surface of MullerHinton agar plate (HiMedia, India). The plates were held at room temperature for $15 \mathrm{~min}$ to allow drying. The discs were placed with $20 \mathrm{~mm}$ gap between them and $15 \mathrm{~mm}$ from the edge of the plates to prevent overlapping of the inhibition zones. The plates were incubated at $37^{\circ} \mathrm{C}$ for $24 \mathrm{~h}$. The diameter of the zones of inhibitions was recorded and classified as resistant, intermediate or susceptible according to the interpretive standards of the Clinical Laboratory Standards Institute (CLSI, 2014)

Eleven antimicrobial disks, i.e. ampicillin (10 $\mu \mathrm{g})$, amoxicillin (30 $\mu \mathrm{g})$, norfloxacin $(30 \mu \mathrm{g})$, chloramphenicol $(30 \mu \mathrm{g})$, vancomycin $(30 \mu \mathrm{g})$, streptomycin $(10 \mu \mathrm{g})$, tetracycline $(30 \mu \mathrm{g})$, sulfamethazine $(300 \mu \mathrm{g})$, lincomycin $(2 \mu \mathrm{g})$ penicillin $(10$ $\mu \mathrm{g})$ and doxycycline $(10 \mu \mathrm{g})$, currently available and commonly used as chemotherapeutic and chemoprophylactic drugs for Salmonella infection in humans and animals were used. The zone of inhibition was measured and reported as susceptible (S) intermediate (I) or resistant (R) in reference to the zone size of the interpretive chart.The selection of the drugs was based on the standards drugs used forthe treatment of salmonellosis (CLSI, 2014) and the availability of these drugs during the research work. Standard strains of $E$. coli ATCC 29522 and ATCC 35218 kindly provided by Ethiopian Public Health Institute were used as a quality control organism throughout the study for antimicrobial susceptibility testing.

\section{Data analysis}

All data collected were entered and coded using Microsoft Excel Spreadsheet. Statistical analysis was made using STATA software version 11.0 (STATACORP, 2009). Descriptive statistics was used to summarize the data. Chisquare and logistic regression analyses were used to assess the association of risk factors with the prevalence of Salmonella. For all risk factors, the level 
with the lowest prevalence was used as a reference category. Those variables with $P$-value $\leq 0.25$ in the univariable logistic regression analysis were further analyzed using multivariable logistic regression after checking for multicollinearity. In all the cases $P<0.05$ was set for significance.

\section{Results}

\section{Prevalence}

The overall prevalence, as well as occurrence of Salmonella at town level in the rectal swab samples of 438 apparently healthy dogs, enrolled in the study was shown in Table 1.

Table 1. Prevalence of Salmonella infection in rectal swab samples of dogs of Ambo, Bako and Gojo towns, West Shoa Zone, Ethiopia.

\begin{tabular}{lccc}
\hline Study towns & No. of dogs examined & $\begin{array}{l}\text { No. } \\
\text { positive }\end{array}$ & \% prevalence (95\% CI) \\
\hline Ambo Town & 238 & 26 & $10.9(7.3-15.6)$ \\
Bako Town & 129 & 15 & $11.6(6.7-18.5)$ \\
Gojo Town & 71 & 7 & $9.9(4.1-19.3)$ \\
Total & $\mathbf{4 3 8}$ & $\mathbf{4 8}$ & $\mathbf{1 1 . 0}(8.2-\mathbf{1 4 . 3})$ \\
\hline
\end{tabular}

\section{Risk factors}

Univariable logistic regression analysis showed that the risk of Salmonella shedding was significantly higher in older dogs than in young dogs $(\mathrm{OR}=2.7$, $P=0.004)$. Similarly, there was a significant difference in the prevalence of Salmonella shedding in dogs between Kebeles of the study areas $(P<0.05)$. Feed type is borderline significant $(P=0.053)$ i.e., the probability of shedding Salmonella is higher in dogs feeding on mixed type of feed (raw animal products and household leftover) than dogs fed on cooked animal products. However, there was no significant difference inthe prevalence of Salmonella with respect to towns, breed, sex, educational status of owners, presence of other animals in the household, and housing system of dogs $(P>0.05)$ (Table 2). 
Table 2. Results of univariable logistic regression analysis of potential risk factors for Salmonellasheddingof dogs in Ambo, Bako and Gojo towns

\begin{tabular}{|c|c|c|c|c|c|}
\hline Variables & Category & $\begin{array}{l}\text { No. pos./tested } \\
(\%)\end{array}$ & OR & $95 \%$ CI & P-value \\
\hline \multirow[t]{3}{*}{ Town } & Gojo & 7/71 (9.9) & 1 & - & - \\
\hline & Ambo & 26/238 (10.9) & 1.1 & $0.5-2.7$ & 0.799 \\
\hline & Bako & 15/129 (11.6) & 1.2 & $0.5-3.1$ & 0.702 \\
\hline \multirow[t]{6}{*}{ Kebele } & Ambo 03 & $2 / 72(2.8)$ & 1 & - & - \\
\hline & Gojo 01 & 7/71 (9.9) & 3.8 & $0.8-19.1$ & 0.102 \\
\hline & Bako 02 & 9/86 (10.5) & 4.1 & $0.9-19.6$ & 0.083 \\
\hline & Bako 01 & 7/66 (10.6) & 4.2 & $0.8-20.8$ & 0.078 \\
\hline & Ambo 01 & 8/63 (12.7) & 5.1 & $1.0-24.9$ & 0.045 \\
\hline & Ambo 02 & $15 / 80(18.8)$ & 8.1 & $1.8-36.7$ & 0.007 \\
\hline \multirow[t]{2}{*}{ Age } & Young & $12 / 198$ (6.1) & 1 & - & - \\
\hline & Old & $36 / 240(15.0)$ & 2.7 & $1.4-5.4$ & 0.004 \\
\hline \multirow[t]{2}{*}{ Breed } & Cross & $6 / 77(7.8)$ & 1 & - & - \\
\hline & Local & 42/361 (11.6) & 1.6 & $0.6-3.8$ & 0.331 \\
\hline \multirow[t]{2}{*}{ Sex } & Female & 8/103 (7.8) & 1 & - & - \\
\hline & Male & 40/335 (11.9) & 1.6 & $0.7-3.6$ & 0.239 \\
\hline \multirow{4}{*}{$\begin{array}{l}\text { Educational } \\
\text { status of the } \\
\text { owner }\end{array}$} & Illiterate & $6(10.5)$ & 1 & - & - \\
\hline & $\begin{array}{l}\text { Primary } \\
\text { school }\end{array}$ & $13(12.12)$ & 1.1 & $0.4-3.0$ & 0.833 \\
\hline & $\begin{array}{l}\text { Secondary } \\
\text { school }\end{array}$ & $14(12.2)$ & 1.3 & $0.6-2.8$ & 0.522 \\
\hline & $\begin{array}{l}\text { Tertiary/ } \\
\text { university }\end{array}$ & $15(9.4)$ & 1.3 & $0.6-2.9$ & 0.502 \\
\hline \multirow{3}{*}{$\begin{array}{l}\text { Presence of } \\
\text { other animals } \\
\text { in the HH }\end{array}$} & No & $21(10.8)$ & 1 & - & - \\
\hline & Yes & 27 (11.1) & 1.0 & $0.6-1.9$ & 0.936 \\
\hline & Indoor & 12/79(15.2) & 1 & - & - \\
\hline \multirow{2}{*}{$\begin{array}{l}\text { Housing } \\
\text { system }\end{array}$} & Outdoor & $22 / 176(12.5)$ & 1.7 & $0.9-3.5$ & 0.130 \\
\hline & Mixed & $14(7.7)$ & 2.2 & $1.0-5.0$ & 0.066 \\
\hline \multirow[t]{2}{*}{ Feed type } & $\begin{array}{l}\text { Cooked } \\
\text { animal feed }\end{array}$ & $1(1.9)$ & 1 & - & - \\
\hline & Mixed & $47(12.2)$ & 7.2 & $1.0-53.5$ & 0.053 \\
\hline
\end{tabular}

The variables town, breed, educational status of dog owners and presence of other animals in the household were excluded from entry into the multivari- 
able logistic regression model due to univariable $P$-values $>0.25$. The variables Kebele, age, sex, housing system, and feed type were all non-collinear with univariable $P$-value $<0.25$ hence entered into the multivariable model. The final multivariable logistic regression model of risk factors analysis revealed that Kebele, age, and feed type had a significant association with Salmonella prevalence and hence are independent predictors $(P<0.05)$ (Table 3$)$.

Table 3. Results of the multivariable logistic regression model for the predictors of Salmonellas hedding in dogs in Ambo, Bako and Gojo towns

\begin{tabular}{|c|c|c|c|c|}
\hline Variables & Category & aOR & 95\% CI & P-value \\
\hline \multirow[t]{6}{*}{ Kebele } & Ambo,03 & 1.0 & - & - \\
\hline & Gojo,01 & 4.1 & $0.9-20.4$ & 0.077 \\
\hline & Bako,02 & 9.0 & $1.9-41.9$ & 0.005 \\
\hline & Bako,01 & 4.9 & $1.0-24.4$ & 0.055 \\
\hline & Ambo,01 & 3.9 & 0..7-19.6 & 0.105 \\
\hline & Ambo, 02 & 3.7 & $0.7-18.9$ & 0.113 \\
\hline \multirow[t]{2}{*}{ Age } & Young & 1.0 & - & - \\
\hline & Old & 2.6 & $1.3-5.3$ & 0.007 \\
\hline \multirow[t]{2}{*}{ Sex } & Female & 1.0 & - & - \\
\hline & Male & 1.7 & 0.8-3.9 & 0.203 \\
\hline \multirow[t]{3}{*}{ Housing } & Indoor & 1.0 & - & - \\
\hline & Outdoor & 2.0 & $1.0-4.3$ & 0.063 \\
\hline & Mixed & 2.2 & $0.9-5.1$ & 0.079 \\
\hline \multirow[t]{2}{*}{ Feed type } & Cooked feed & 1.0 & - & - \\
\hline & Mixed & 8.6 & $1.1-65.4$ & 0.037 \\
\hline
\end{tabular}

\section{Antimicrobial susceptibility tests}

The result of antimicrobial susceptibility testing of Salmonella isolated from dogs using 11 selected antimicrobial drugs is presented in Table 4. Fifteen Salmonella isolates proportionally selected among the whole isolates of the three townswere tested for antimicrobial susceptibility testing. The highest level of resistance was observed for ampicillin (100\%), penicillin (93.3\%), streptomycin $(80 \%)$ and lincomycin $(66.7 \%)$. All isolates were susceptible to norfloxacin. 
Table 4. Results of antimicrobial susceptibility testing of Salmonella isolates $(n=15)$ from rectal swab samples of dogs in Ambo, Bako and Gojo towns

\begin{tabular}{|c|c|c|c|c|}
\hline \multirow{2}{*}{$\begin{array}{l}\text { Antimicrobial } \\
\text { class }\end{array}$} & \multirow{2}{*}{$\begin{array}{l}\text { Antimicrobial discs } \\
\text { and concentration }\end{array}$} & \multicolumn{3}{|c|}{ Salmonella isolates $(n=15)$} \\
\hline & & $\begin{array}{l}\text { No Resistant } \\
(\%)\end{array}$ & $\begin{array}{l}\text { No } \\
\text { Intermediate } \\
(\%)\end{array}$ & $\begin{array}{l}\text { No } \\
\text { susceptible } \\
(\%)\end{array}$ \\
\hline Aminoglycosides & Streptomycin $(10 \mu \mathrm{g})$ & $12(80)$ & $(0)$ & $3(20)$ \\
\hline \multirow[t]{3}{*}{ B-lactams } & Amoxicillin $(20 \mu \mathrm{g})$ & $9(60)$ & $5(33.3)$ & $1(6.7)$ \\
\hline & Ampicillin $(10 \mu \mathrm{g})$ & $15(100)$ & $0(0)$ & $0(0)$ \\
\hline & Penicillin $(10 \mu \mathrm{g})$ & $14(93.3)$ & $0(0)$ & $1(6.7)$ \\
\hline Phenicols & $\begin{array}{l}\text { Chloramphenicol (30 } \\
\mu \mathrm{g})\end{array}$ & $3(20)$ & $11(73.3)$ & $1(6.7)$ \\
\hline \multirow[t]{2}{*}{ Tetracyclines } & 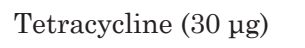 & $13(86.7)$ & - & $2(13.3)$ \\
\hline & 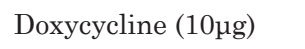 & $6(40)$ & $8(53)$ & $1(6.7)$ \\
\hline $\begin{array}{l}\text { Folate pathway } \\
\text { inhibitors }\end{array}$ & $\begin{array}{l}\text { Salphametazone } \\
(25 \mu \mathrm{g})\end{array}$ & $2(13.3)$ & $0(0)$ & $13(86.7)$ \\
\hline Fluoroquinolones & Norfloxacin $(10 \mu \mathrm{g})$ & $0(0)$ & $0(0)$ & $15(100)$ \\
\hline $\begin{array}{l}\text { Lincosimide } \\
\text { antibiotics }\end{array}$ & Lincomycin $(2 \mu g)$ & $10(66.7)$ & $4(26.7)$ & $1(6.7)$ \\
\hline Glycopeptides & Vancomycin $(30 \mu \mathrm{g})$ & $8(53.3)$ & $6(40)$ & $1(6.7)$ \\
\hline
\end{tabular}

Six different multidrug resistance patterns were observed among Salmonella isolates tested. About $13.3 \%$ of Salmonella isolates tested showed multidrug resistance to six different classes of drugs. Two isolates were resistant to six antimicrobial classes (Table 5).

Table 5. Multiple drug resistance pattern of Salmonella isolates from rectal swab samples of dogs in Ambo, Bako and Gojo towns

\begin{tabular}{llc}
\hline Number & $\begin{array}{l}\text { Antimicrobial resistance pattern } \\
\text { (No.) }\end{array}$ & No. of isolates resistant (\%) \\
\hline Three & AMP,TET, S & $1(6.7)$ \\
Four & AMP,TET, PB, S & $2(13.3)$ \\
Four & AMP,TET, PB, VA & $7(46.7)$ \\
Five & AMP,TET, PB, VA, C & $2(13.3)$ \\
Six & AMP,TET, PB, VA, C, S & $1(6.7)$ \\
Six & AMP,TET, PB, VA, S, SXT & $2(13.3)$ \\
\hline AMO: Amoxicillin, C: Chloramphenicol, PB: Lincomycin, NOR: Norfloxacin, P: Penicillin, VA: Vancomycin, \\
SXT: Sulfamethazine, S: Streptomycin, AMP: Ampicillin, TET: Tetracycline, DOX: Doxycycline.
\end{tabular}




\section{Discussion}

Dogs have been reported to be the carrier of Salmonella worldwide which have the potential to serve as sources of exposure or infection for other animals (Carter and Quinn, 2000). It was reported that the intestinal carriage of Salmonella by dogs is more common than the prevalence of clinical disease (Kozak et al., 2003). The frequency of rectal swab isolation of Salmonella from clinically healthy dogs was reported to be between $0.0 \%$ and $43.0 \%$ (Carter and Quinn, 2000; Sanchez et al., 2002).

In Ethiopia, like many other developing countries, dogs are predominantly kept for guarding/security and hunting. Feeding, housing, and health care their owners provide are generally inadequate, consequently, most dogs have free access to feed and contaminate the environment through open-air defecation (Castro et al., 2019). The percentage of Salmonella shedding in this study (11.0\%) might be an underestimate due to the fact that culture-negative dogs might still be sub-clinical shedders since the bacteria are shed intermittently and sampling was done only once and swab rather than faeces was examined (Carter and Quinn 2000).

The present study indicated an overall Salmonella prevalence of $11.0 \%$ which is higher than the reports ofSeepersadsinghet al. (2004) in subclinical dogs (3.6\%) in Trindad, Amadi et al.(2018)in the feces of non-diarrheic owned dogs in Grenada (5.6\%) and from apparently healthy dogs in Midlands region of the United Kingdom (0.2\%) (Lowden et al., 2015). Kiflu et al. (2017) from Addis Ababa reported 11.7\% Salmonella prevalence in apparently healthy dogs, which is in accord to the present study. However, Aliyi et al. (2018) reported higher prevalence from dogs of Holeta town.

This difference in prevalence of Salmonella in dogs among different studies in various countries mightbe attributed to variation in hygiene, sanitation procedures, or seasonof sampling (Lowden et al., 2015), the number of dogs sampled, type of sample, geographical properties, sampling strategies and isolation methods employed (Seepersadsingh et al., 2004).

Studies conducted on prevalence of Salmonella in Ethiopia reported prevalence of $7.8 \%$ in food items (Zewdu and Cornelius, 2009) and $17.7 \%$ from carcass swab (Weldo et al., 2015) while prevalence of 7.4\% from stool samples (Zewdu and Cornelius, 2009), 12\% from abattoir workers and meat retailers (Ejo 
et al., 2016) were reported. These reports indicate that Salmonella is prevalent in animals, humans and food items in different parts of Ethiopia that could support the present study in that Salmonella can be prevalent in dogs (Addis et al., 2011; Wabeto et al., 2017).

Dogs shedding Salmonella might have acquired the organism from their feed or from materials ingested during scavenging. Scavengers exposed to many contaminated materials are likely to harbor more Salmonella serovars than non-scavengers kept under hygienic conditions. The hypothesis behind was that the prevalence of Salmonella would be higher in dogs eating a mixed diet than eating cooked animal products. In the present study, the prevalence of Salmonella was significantly higher in dogs on the mixed diet (raw animal products, cooked animal products, andhousehold leftover) 47/385(12.2\%) as compared to dogs on cooked animal product diet 1/53(1.9\%) (Table 2).Salmonella has been isolated from $80.0 \%$ of bone and raw food diets and from $30 \%$ of the fecal samples from dogs fed the diet (Joffe and Schlesinger, 2002). Therefore, it implies that dogs fed raw animal products might be a source of environmental contamination with Salmonella.

In this study, age of dogs was another risk factor for Salmonella shedding, in that the prevalence was significantly higher in older (15.0\%) than younger dogs $(7.8 \%)(P<0.05)$. This could probably be associated with the longer time of exposure of older dogs to different risk factors of Salmonella and insufficiency of the immune response in older dogs to completely eliminate the bacteria from their body, in which case they carry the bacteria sub-clinically (Radostitset al., 2006).Unlike this study, Castro et al. (2019) from Mexico recently reported that dog under one year aremore likely to acquire Salmonella than dogs older than one year. On the other hand, Aliyi et al. (2018) did not find a significant difference in the prevalence of Salmonella between age groups examined.

There was also a significant difference in the rate of isolation of Salmonella between Kebeles, which might be due to more availability of contaminated food leftover from customers in hotels, restaurants, and other cafes in those Kebeles where the isolation rate was higher. The difference might also be due to the high number of butchers and meat retailers, which might lead to more contamination of dog feeds with Salmonella in those Kebele where the isolation rate was higher. 
In the present study, a significant difference in the shedding of Salmonella was not found with respect to the housing system of dogs. However, studies frequently report that faecal shedding is less frequent in household pet dogs as compared to those inkennels and stray dogs (Carter and Quinn 2000).

The development of multiple antimicrobial resistance seen in this study signals an important health threat in both the veterinary and public health sectors as it limits antimicrobial drugs available for effective control of Salmonella infections. Thus, regular monitoring of antimicrobial resistance is important because of the public health impact (Magiorakos et al., 2012) and the influence of such testing on the choice of antimicrobial drugs to treat clinical cases (Seepersadsingh et al., 2004).

The Salmonella isolates in this study had marked antimicrobial resistance to sixof the eleven antimicrobials tested (i.e. ampicillin, tetracycline, streptomycin, lincomycin, penicillin, and amoxicillin) and two isolates had multidrug resistance to six antimicrobials. Such high level of antimicrobial resistancein towns where dog owners do not visit veterinary clinics for health issues of their dogsis alarming as these dogs could potentially facilitate spreading of antimicrobial-resistant Salmonella to humans and other animals. A previous study from apparently healthy dogs visiting veterinary clinics in Addis Ababa for anti-rabies vaccination reported $30.9 \%, 38.1 \%, 59.5 \%$ resistance for ampicillin, streptomycin, and oxytetracyclines (Kiflu et al., 2017) which is lower than the present study.Since dogs can acquire Salmonella from their feed, especially raw animal products, they could be infected or receive drug-resistant Salmonella from the food chain or from the environment they are living because of improper use of antimicrobials and residues in animal products. In addition, the drug resistance of Salmonella from dogs can vary widely depending on the geographic area, level of sanitation, public awareness, socioeconomic status of owners and possibly, serovars (Kiflu et al., 2017). In the present study, norfloxacin had the best antimicrobial activity against Salmonella isolates. All 15 $(100 \%)$ isolates were susceptible to norfloxacin. This result was comparable to the previous report on isolates of Salmonella from dogs (Seepersadsingh et al., 2004).

The detection of Salmonella from rectal swab samples of Ethiopian dogs is of great significance towards the understanding of the possible role of dogs in the environmental spread and transmission to other animals and people who have close contact with carrier dogs. Such transmission is more likely to occur in 
children and immunosuppressed individuals who are at higher risk of infection (Sato et al., 2000).

The current study did not identify Salmonella isolates to serotype level due to lack of laboratory facility. Not all antimicrobial drugs recommended for Salmonella were included in the antimicrobial susceptibility testing due to limited availability. Nevertheless, despite these limitations, the results on prevalence, risk factors, and antibiogram are still important since there is limited information in Ethiopia.

\section{Conclusions}

The prevalence of Salmonella in rectal swab samples of apparently healthy dogs of the study towns was moderately high. Age of dogs, Kebeles where dogs live and type of dog feeds are predictors of Salmonella isolation. The high rate of antimicrobial-resistant Salmonella could be a potential threat for humans and animals in the study areas.Establishment and enforcement of legislation, which encourages responsible dog ownership, education of dog owners, and further detailed studies on serotyping, molecular epidemiology of Salmonella isolates and surveillance of antimicrobial resistance are suggested.

\section{Ethics approval and consent to participate}

The ethical committee for animal experimentation of the Ambo University, Ethiopia (Ref. No. RD/AREC/004/2016) approved this research project. All animals were handled strictly in accordance with the good animal handling practice in order to minimize animal sufferings during sampling. Informed verbal consent was obtained from the dog owners.

\section{Acknowledgments}

This study was supported by Ambo University, Research and community service vice president office. We greatly thank dog owners and workers of animal health centers in Ambo, Bako and Gojo towns for their cooperation during sample collection.

\section{Conflict of interest}

There is no conflict of interest to declare 


\section{References}

Abdi, R. D., Mengstie, F., Beyi, A. F., Beyene, T., Waktole, H., Mammo, B. and Abunna, F., 2017. Determination of the sources and antimicrobial resistance patterns of Salmonella isolated from the poultry industry in Southern Ethiopia. BMC Infect. Dis., 17, 352-352.

Addis, Z., Kebede, N., Worku, Z., Gezahegn, H., Yirsaw, A. and Kassa, T., 2011. Prevalence and antimicrobial resistance of Salmonella isolated from lactating cows and in contact humans in dairy farms of Addis Ababa: a cross-sectional study. BMC Infect. Dis., 11:222.

Aliyi, S., Hirpa, E. Zewude, O. and Equar, Y. (2018).Isolation and Identification of Salmonella from Apparently Healthy Pet Dogs in Holeta Town, Western Shoa, Ethiopia.Curr Trends Biomed. Eng and Biosci 15(2): 555907. DOI: 10.19080/CTBEB.2018.15.555907.

Amadi, V. A., Hariharan, H., Arya, G., Matthew-Belmar, V., Nicholas-Thomas, R., Pinckney, R., Sharma, R. and Johnson, R. 2018. Serovars and antimicrobial resistance of non-typhoidal Salmonella isolated from non-diarrhoeic dogs in Grenada, West Indies. Vet. Med. Sci., 4, 26-34.

Bekele, D. and Kebede, K., 2016. On-Farm Phenotypic Characterization of Indigenous Cattle in Bako Tibe and Gobu Sayo Districts of Oromia Region, Ethiopia. J.Biol., Agri. and Healthcare. 6 (19), 94-103.

Carter, M. E. and Quinn, P. J. 2000. Salmonella infections in dogs and cats, Salmonella in domestic animals, 231-244.

Castro, N. K.M., Muñoz, E.T., García, G.F., Herrera Ramírez, J.C., Valencia, G.L., Medina Basulto, G.E., Pujol Manríquez, L.C., Rentería Evangelista, T.B. (2019). Prevalence, risk factors, and identification of Salmonella spp. in stray dogs of northwest Mexico. Austral. J. Vet. Sci., 51, 37-40.

Chen, B. Y., Wang, C. Y., Wang, C. L., Fan, Y. C., Weng, I. T. and Chou, C. H., 2016. Prevalence and Persistence of Listeria monocytogenes in Ready-to-Eat Tilapia Sashimi Processing Plants. J. Food. Prot., 79, 1898-1903.

CLSI, 2014. M100-S24 Performance Standards for Antimicrobial Susceptibility Testing: Twenty Fourth Information Supplement, 68-150.

Crump, J. A., Luby, S. P. and Mintz, E. D., 2004. The global burden of typhoid fever. Bull. World Health Organ., 82, 346-353.

CSA (Central Statistics Agency of Ethiopia), 2007. Population and Housing Census of Ethiopia. http://www.csa.gov.et/newcsaweb/images/documents/surveys/Population $\% 20$ and $\%$ 
CSA, 2015. Cities \& Towns [Online]. Available: https://www.citypopulation.de/Ethiopia.html [Accessed October 19, 2018].

CSA, 2008. Summary and Statistical Report of the 2007 Population and Housing Census Results. Addis Ababa, Ethiopia

Eguale, T., Gebreyes, W. A., Asrat, D., Alemayehu, H., Gunn, J. S. and Engidawork, E., 2015. Non-typhoidal Salmonella serotypes, antimicrobial resistance, and coinfection with parasites among patients with diarrhea and other gastrointestinal complaints in Addis Ababa, Ethiopia. BMC Infect. Dis., 15, 497.

Ejo, M., Garedew, L., Alebachew, Z. and Worku, W., 2016. Prevalence and antimicrobial resistance of Salmonella isolated from animal-origin food items in Gondar, Ethiopia. Biomed. Res. Int., 2016.

Feasey, N. A., Dougan, G., Kingsley, R. A., Heyderman, R. S. and Gordon, M. A., 2012. Invasive non-typhoidal salmonella disease: an emerging and neglected tropical disease in Africa. Lancet, 379, 2489-2499.

Ferede, B., Desisa, F., Feleke, A., Tadesse, G. and Moje, N. 2015. Prevalence and antimicrobial susceptibility of Salmonella isolated from apparently healthy slaughtered goats at Dire Dawa municipal abattoir, Eastern Ethiopia. J. Microbiol. Antimicrob., 7, 1-5.

Finley, R., Ribble, C., Aramini, J., Vandermeer, M., Popa, M., Litman, M.and ReidSmith, R. 2007. The risk of salmonellae shedding by dogs fed Salmonella-contaminated commercial raw food diets. Can. Vet. J., 48, 69-75.

International Organization for Standardization (ISO) 6579, 2002. Microbiology of Food and Animal Feeding Stuff-Horizontal Method for the Detection of Salmonella, International Organization for Standardization (ISO), Geneva, Switzerland, 4th edition, Pp. 897-902.

ISO, 2007. ISO 6579 Microbiology of food and animal feeding stuff - Horizontal method for detection of Salmonella spp. in animal faeces and in environmental samples from the primary production stage, 14 .

Joffe, D. J., and Schlesinger, D. P., 2002. Preliminary assessment of the risk of Salmonella infection in dogs fed raw chicken diets. Can. Vet. J., 43, 441-442.

Kiflu, B., Alemayehu, H., Abdurahman, M., Negash, Y. and Eguale, T., 2017. Salmonella serotypes and their antimicrobial susceptibility in apparently healthy dogs in Addis Ababa, Ethiopia. BMC Vet. Res., 13, 134.

Kirk, M. D., Pires, S. M., Black, R. E., Caipo, M., Crump, J. A., Devleesschauwer, B., Döpfer, D., Fazil, A., Fischer-Walker, C.L., Hald, T., Hall, A.J., Keddy, K.H., Lake, R.J., Lanata, C.F., Torgerson, P.R., Havelaar, A.H. and Angulo, F.J. 2015. Correction: World Health Organization Estimates of the Global and Regional Disease 
Burden of 22 Foodborne Bacterial, Protozoal, and Viral Diseases, 2010: A Data Synthesis. PLoS Med., 12, e1001940.

Kozak, M., Horosova, K., Lasanda, V., Bilek, J. and Kyselova, J., 2003. Do dogs and cats present a risk of transmission of salmonellosis to humans? Bratisl. Lek. Listy., 104(10), 323-328.

Lowden, P., Wallis, C., Gee, N. and Hilton, A., 2015. Investigating the prevalence of Salmonella in dogs within the Midlands region of the United Kingdom. BMC Vet. Res., 11, 239.

Magiorakos, A.-P., Srinivasan, A., Carey, R.B., Carmeli, Y., Falagas, M.E., Giske, C.G., Harbarth, S., Hindler, J.F., Kahlmeter, G., Olsson-Liljequist, B., Paterson, D.L., Rice, L.B., Stelling, J.,Struelens, M.J.,Vatopoulos, A., Weber, and Monnet, D.L. (2012).Multidrug-resistant, extensively drug-resistant and pandrug-resistant bacteria: an international expert proposal for interim standard definitions for acquired resistance.Clin Microbiol Infect., 18, 268-281.

Marami, D., Hailu, K. and Tolera, M., 2018. Prevalence and antimicrobial susceptibility pattern of Salmonella and Shigella species among asymptomatic food handlers working in Haramaya University cafeterias, Eastern Ethiopia. BMC. Res. Notes, 11, 74-74.

Mcgavin, D. M., Carlton, W. W. J. and Zachary, J. F. 2001. Thompson's Special Veterinary Pathology, Mosby, Philadephia, USA.

Ojo, O. E., and Adetosoye, A. I., 2009. Salmonella Typhimurium infection in diarrhoeic and none-diarrhoeic infection dogs in Ibadan, Nigeria dogs in Ibadan, Nigeria. Veterinarski Arhiv., 79, 371-377.

Quinn, P., Markey, B., Leonard, F., Fitzpatrick, E., Fanning, S. and Hartigan, P., 2011. Veterinary Microbiology and Microbial Disease, $2^{\text {nd }}$ Edition, Hometra, Syndey.

Radostits, O. M., Gay, C.C., Hinchcliff, K. W. and Constable, P. D. 2006. Veterinary Medicine E-Book: A textbook of the diseases of cattle, horses, sheep, pigs and goats, $10^{\text {th }}$ editions, Saunders Ltd., USA.

Sanchez, S., Hofacre, C. L., Lee, M. D. and Maurer, J. J., 2002. Animal sources of salmonellosis in humans. JAVMA, 221, 492-497.

Sato, Y., Mori, T., Koyama, T. and Nagase, H. (2000). Salmonella Virchow infection in an infant transmitted by household dogs. J. Vet. Med Sci,. 62 (7), 767-769.

Seepersadsingh, N., Adesiyun, A. A. and Seebaransingh, R., 2004. Prevalence and antimicrobial resistance of Salmonella spp. in non-diarrhoeic dogs in Trinidad. J. Vet. Med. B. Infect. Dis. Vet. Public Health, 51, 337-342. 
Statacorp, T., 2009. Statistical Software: Release 11 College Station, College Station, TX: StataCorp LP., USA.

Thrusfield, M., 2007. Veterinary Epidemiology; Describing disease occurrence, $3^{\text {rd }}$ editions, Blackwell Science Ltd, Oxford, UK.

Wabeto, W., Abraham, Y. and Alemayehu, A. A., 2017. Detection and identification of antimicrobial-resistant Salmonella in raw beef at Wolaita Sodo municipal abattoir, Southern Ethiopia. J. Health Popul. Nutr., 36-52.

WHO, (2012). The evolving threat of antimicrobial resistance: options for action. World Health Organization. https://apps.who.int/iris/handle/10665/44812.

Wikipedia. 2019. Aging in dogs. Retrieved from https://en.wikipedia.org/wiki/Aging_in_ dogs, Accessed June 10, 2018.

Zewdu, E. and Cornelius, P., 2008. Antimicrobial resistance pattern of Salmonella serotypes isolated from food items and personnel in Addis Ababa, Ethiopia. Trop. Anim. Health Prod., 41, 241-249 